\title{
Psychiatric and neurologic lessons in the oldest Persian medical liber. Akhawayani Bokhari (?-died 983 AD), physician of insane.
}

\author{
Mohammadreza Ardalan ${ }^{1}$
}

Received: 27 November 2016 / Accepted: 6 December 2016/Published online: 24 April 2017

(C) Springer-Verlag Berlin Heidelberg 2017

\section{Introduction}

There is a rich history of medicine in Persia. Experiences and knowledge of medicine in this area continued and connected to a new era named Islamic golden age (9th-twelfth century AD). Great Persian physicians such as Raban Tabari, Rhazes, Haly Abbas, Akhawayani Bokhari, Avicenna, and jurjani all grew up, studied and worked in this period.

Akhawayani Bokhari (Abubakr Rabi ibn Ahmad alAkhawayni al-Bokhara,?-died 983 AD), most likely worked and lived all his life in Bukhara, a city currently at the Republic of Uzbekistan. Bukhara was prospered during the Samanid dynasty (875-999 AD). Samanids established an autonomic state in north east of Persia and revived the Persian literature and traditions that had lost its official status after the Arab conquest in seventh century. During the Samanid rulers Persian language and culture revived and started to be used in art and sciences with increasing nationalistic vigor. Akhawayni was the student of one of the razes follower. He collected his medical experiences in a compendium named; Hidayat al-Mutaallemin fi al-Tibb (Learner's Guide to Medicine). In this book he has referenced to his predecessors, Galen, Hippocrates, Rhazes, Yahya ibn Sarabyun, Dioscurides, Archigenes and Aristoteles, (1-3) Hidayat al-Mutaallemin fi al-Tibb is the oldest treatise on medicine written in Persian .

Hidayat Al-Mutallimin fi al-Tibb consists of 185 chapters (Baabe). Five chapters are completely devoted to psychiatry,

Mohammadreza Ardalan

ardalan34@yahoo.com

1 Kidney Research Center, Tabriz University Of Medical Sciences, Tabriz, Iran including's; Ba ab mania (chapter on Mania), baabe Malikholia( chapter on Melancholia), baabe Kaboos (chapter incubus), Baabe Raja(chapter on pseudocyesis), Baabe Ghotrab(chapter on Hebpherenia/schizophrenia), baabe Honag-Al -Rahem ( conversion disorder ), there are also many psychiatric notes distributed in another parts of the text (4).

As he quotes in his book, he had great success in the treatment of psychiatric and melancholic patient, and for this reason he was named pezeshk divanegan ( physician for the insane ).

The oldest preserved script of this book (1058 AD) is the manuscript of the Bodleian Library in Oxford, The second, and third scripts are copies of the Fatih Library of Istanbul and the Iranian National Library of Malek in Tehran in succeeding $(5,8)$. Jalal Matini, a contemporary Persian scholar, compared the tree manuscripts and published a literary edition in 1965 (4). The following passages are extracted from this edition. Each passage is followed by simple explanation.

\section{Passages}

\section{Baabe Malikholia (a chapter on melancholia)}

... And melancholia is a fear, without any reason and there is no fever and their speech are meaningless sometimes laughing and sometimes crying and when you asking them [a question] they cannot respond you, and[ they] answer you incorrectly...[4].

...most of the time he is down without any reason, and he is paranoid, and losses his self-steam and hop. All of those are the symptoms of melancholia, and there are visual hallucination...4) 
... Ghotrab is a Madness that destroys the insight, because of great dryness....the symptoms of this disease[are as the followings]; the patient is sad, with open eyes looking at people, and he is silent and never utters any word. he is wondering and running in the deserts and his foots are injured .... and I treated one of this patients with topical ointments and oils and $i$ delivered food and medicine orally by an instrument [ funnel shape] that I made it from the horn of ox .... [4]

...some of these patients believe that they know about the future, and they are profit and revelation is near/ other believes that is king and running many territories. Another one believes that their body is made from clay, some of them have the constant fear that sky is going to fall on them and all the time they put their hand on their head... [4]

...do not loss your hope and I treated many of those patients. They improved with my treatment, and I was named" pezeshk divanegan "(physician of insane), and during thirty years [of my experience] I managed many of them,,,[4]

A mental disturbance characterized by decreased memory, inability to focus on modalities, impaired attention, mood alternation from dysphonia to anxiety and euphoria has been described in above passages. The condition is not accompanied with fever (it is not a feverish delirium). Associated clinical feature have been described. Include; disorganized though, tangenitality, incoherence and perceptual disturbance such as illusion and hallucination.

Reduced emotional responsiveness, blunted affect, apraxia to carry out tasks, Loss of insight, incoherent behavior, bizarre and incorrect answer to questions, and mute state all are symptoms of schizophrenia described in modern psychiatry books. Emotional disturbances including; perplexity, depression and auditory hallucination have been mentioned in above passages. A prominent and vivid components of illusion that is a distorted sensation has been mentioned in above passages. Disordered thought content, persecutory grandiosity with religious ideas, distorted thought process, flight of idea all are vividly obvious above in Akhawayani,s description (5).

\section{Baabe raja (a chapter on false pregnancy)}

... In Persian Raja means desire in this situation a women feels she is pregnant while actually she is not, but she has a great desire and hope to be pregnant. And there are differences between this condition and true pregnancy. [in false pregnancy] the abdomen is swollen and heavy. Mensuration is stopped, but abdominal palpations shows a hard abdomen without any fetal movement. Gradually the abdomen became heavily inflamed and finally creates a condition similar to dropsy [generalized edema] ....[4]

pseudocyesis or false pregnancy is a false belief. In these situation women believes she is pregnant. . This unusual condition accounts for up to six out of every 22,000 live births. Only recently it is begun to understand the psychological roots of this condition. Women with pseudocyesis have many symptoms of pregnancy. When a woman feels an intense desire to become pregnant, which happens after a long period of infertility and repeat miscarriages, her body may produce some pregnancy signs, such as a swollen belly and enlarged breasts. It seems that the intense desire is the trigger for the release of pregnancy hormones such as estrogen and prolactin lead to actual pregnancy symptoms. In the Akhawayni,s quotation the sign and symptoms of pseudocyesis are well described. And considering the intense desire as the origin of the disease is similar to what does exist in modern medical texs $(5,6)$.

\section{Baabe Khonag AL Rahem (a chapter on conversion disorder)}

...khonag alrahem... And this conditions happens for a women ,she fells suffocation, her breath is shortened, cannot utter any word, and finally reachs unconscious state, and this condition[khonag alrahem] has similarities with convulsion, but there are differences. In this condition [khonag alrahem] ] the patients judgment is intact but in the other [ convolution] it is impaired. Patients Inability to speak is similar to convolution, and in convolution there are excessive salivation [saliva dribbling] while in this situation[[khonag alrahem] this condition[excessive salivation] dose not happen... [4]

Here we have quoted and then translated passages attributed to Khonag AL Rahem ( Uterine obstruction), that actually describe.

Above passages describe a conversion disorder. It is also known as somatization. Hysteria or dissociative reaction. The prevalence of conversion disorder is ten times more common in women than men, and because of its frequentness in women it was considered a female reproductive organ related disorder." khonag alrahem" (uterine contraction)

Khonag AL Rahem is a misnomer, and means uterine obstruction, but actually it describes the concept of conversion disorder. A disturbance of body functioning that is not compatible with anatomy and pathophysiology. Conversion typically occurs in the setting of stress and sometimes produces considerable dysfunction such as total paralysis, blindness like condition. Hysteria illustrates the connection between neurology and psychiatry. Despite of those vivid symptoms the attributed signs are undetectable, and are not consistent and reproducible structural lesion.

Conversion disorders are more common in rural area, among low socioeconomic and less educated persons. Anxiety and depressive disorders are associated comorbid conditions. $(5,7)$. Differential diagnosis of true convulsion from hysteria is well described by Akhawayni, and loss of consciousness and excessive salivation are attributed to true convulsion. 
Babe kaboos, and Mania (chapter on incubus and mania)

describe a nightmare and a delirium condition (4).

... And there is a disease that we should comprehend before [understanding] the convolution. And incubus is heralding sign of convolution. ... During the sleep [patient] feels suffocation and this disease is named sikajeh in bokharian dialect and Fadranjak in soghdian,s language. ... this condition [incubus] is similar to Sarsam...it makes the person fearful, paranoid and finally makes them insane and this condition [Sarsam] happens after high fever,and its treatment is similar to phrenitis( meningo-encephalitis). [4]

Nightmare or night-terror is a frightening dream from which person awaken scared. it often happens during the time of stress and illness, and person sit up in bed with a frightening expression with the sense of intense terror. Night terrors may reflect a neurological abnormality in the temporal lobe, and could be a symptom of temporal lobe epilepsy (5). In the second part of the above passages a delirium status combined with consciousness impairment, mood abnormalities and perception impairment has been described. Brain trauma, drug side effects, encephalitis and meningitis are the most common causes of delirium (5). in the above passages the connection between delirium and encephalitis is well illustrated.

\section{Concept of melancholia in art and medicine}

The magnitude of the clinical features of Melancholia has consistently attracted the attention of physicians through the history (Fig. 1 and Cover figure ). Akhawayani;s approaches to the psychiatric disorders is similar to his view toward other organ system disorder, and comparable with modern outlook toward these abnormalities. Delusion, auditory and visual hallucinations, catatonia and hebepherenia are vividly described. Many years after Akhawayani in late nineteen century Catatonia and Hebephrenia were described by Kahlbaum and Ewald Hecker and then it entered into modern psychiatric classification systems and twentieth-century notions of schizophrenia. $(5,8)$. Novel experience on oral food and medicine delivery through a conduit made from cows horn shows a physical approach to psychiatric problems. (4).

\section{Delusion, conversion disorders , and hysteria along the history}

Pseudocyesis false pregnancy or delusional pregnancy has been documented since antiquity. Hippocrates gave the first written account. When he recorded some women with this disorder. False pregnancies was also known during the middle ages and in those time mistook with fibroid tumors, molar pregnancy or ovarian cancer John Mason Good coined the

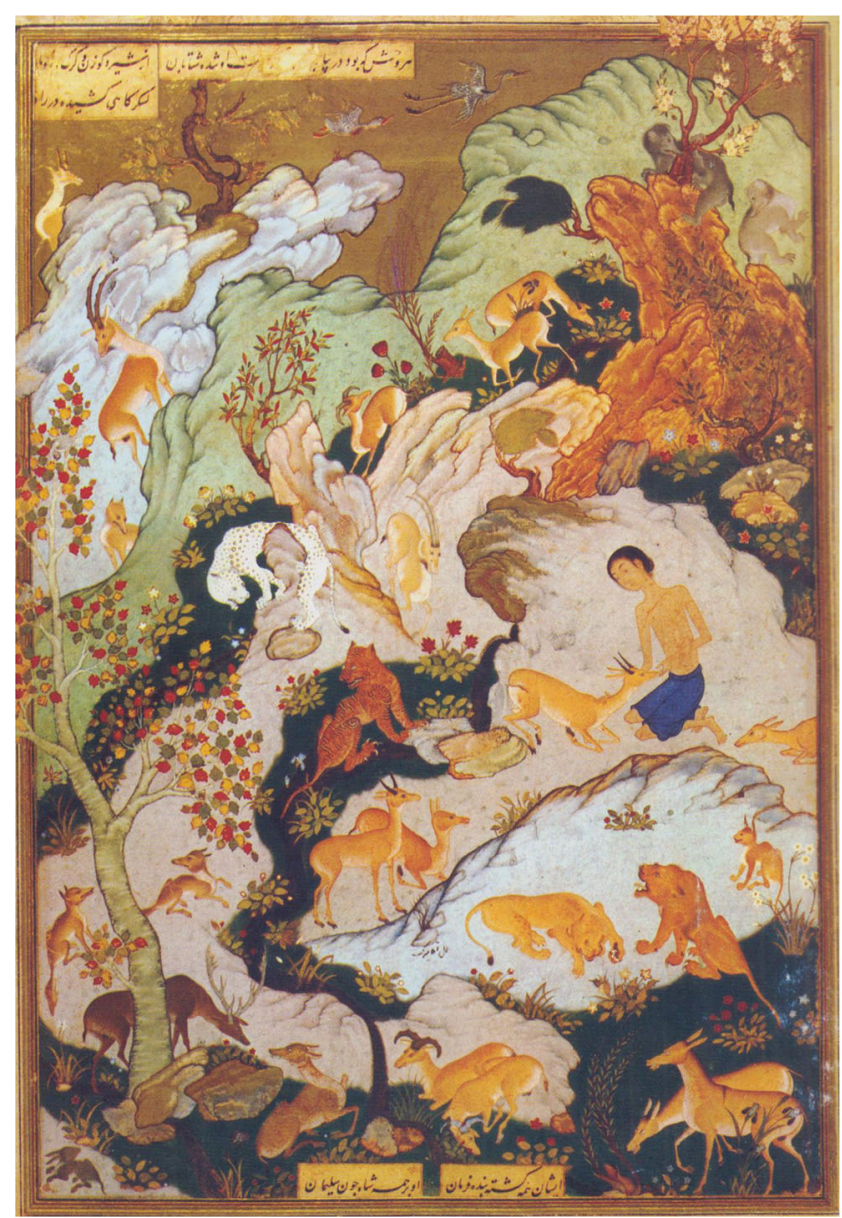

Fig. 1 and Cover figure Persian Miniature of "Madjnun among the beast "that is a depiction of the legend of Layli and Madjnun ,a Persian romance versified by Nezami of Gandja in 1188. A.D. Madjnun is made mad by his love of Laila, he critically rejected, he flees to the desert, and makes friend with animals. in Persian the word of Madjnun is equal to Melancholia and Hebephrenia (concept of adolescent insanity). The human object (Madjun) in this picture, is small, semi-naked, cachectic and frail,. Completely disrupted from human society, and within the wild life. Slopes, curves, curling rivers, dazzling flowers, bright color birds and beasts. All create extremely fine elaboration to show the whole wildness and distance from the human life. Painted by Mir Sayyed Ali (Aqa Mirak) a prominent Persian miniaturist of Tabriz school during the reign of Șafavid Shāh Țahmāsp court(Reign 1524-1576). This miniatures belongs to Khamseh of Nizami collection in the British Museum, London. (www.islamicmanuscripts.info. Courtesy of British museum www.britishmuseum.org)

term pseudocyesis from the Greek words pseudes (false) and kyesis (pregnancy) in 1923 (9)

Delusions are false and firm ideas and cannot be corrected by reasoning. They are related to patient's educational and cultural background. It is a mode of adaptation to stress and serves a metaphorical or allegorical function in which the patient portrays his or her problems and often disregarded in the context of its apparent illogicality. In this condition often the wish-fulfilling function of delusions are apparent. Loss of love, and loss or lake of fertility power operate in the development of delusion of pregnancy (10-13) 
Hysteria was known Since the Greco-Roman period, but the nature of hysterica was the source of controversy. There is no objective signs and the affected person very soon restore his normal activity. During the different, social changes, prosperity, deprivation and gender issues did influence scientific theories. Connection between female reproductive organ and disease condition is a gender related polemic. Sydenham and Willis in the seventeenth century considered the importance of hysteria. During the nineteenth century description of hysteria was done by jean Martin Charcot and his followers including; Babinski , Gilles del la Tourette and Sigmund Freud. (14)

The history of medicine stimulates humanistic qualities that make the practice of medicine unique. Similar to other knowledge past experiences and even wrong medical theories are contribute to our current scientific outlook. Akhawayani,s approach toward the psychiatric problems are based on clinical manifestations, differential diagnosis and judicious treatment. His approach is practical. He implements predecessors knowledge and his own experiments and it is far from theological interpretations.

\section{References}

1. Ardalan MR (2007) Diseases of the kidney in medieval Persia theHidayat of Al-Akawayni. Nephrol Dial Transplant 22:3413-3421

2. Khodadoust K (2012) Discourse on pulse in medieval Persia-the Hidayat of Al-Akhawayni (?-983 AD). Int J Cardiol 166:289-293

3. Khodadoust K (2013) Dental and oral diseases in medieval Persia, lessons from Hedayat Akhawayni. J Med Ethics Hist Med 6:9-13

4. Matini J (1965) Hidayat al-Mutaallimin fi al-Tibb by Abubakr Rabi ibn Ahmad al-Akhawaynial-Bukhari. [in Persian] Mashhad: Mashhad University Press

5. Sadock B (2003). Kaplan \&sadock,s synopsis of psychiatry,behavioral sciences /clinical psychiatry. ninth h edition. Lippincott Williams \& wilkins

6. Shoja MM (2007) The disorder of love in the canon of Avicenna (a.D. 980-1037). Am J Psychiatry 164:228-229

7. Ardalan MR (2012) Lexicon of Persian medical terms in olden medical pandects. Shervin Publication, Tabriz

8. Karma A (2012) Hebephrenia: a conceptual history. History of Psychiatry 23:387-403

9. Cohen LM (1982) A current perspective of pseudocyesis. Am J Psychiatry 139:1140-1144

10. Cohen L (1982) A current perspective of pseudocyesis. Am J Psychiatry 139:1140-1144

11. Hardwick PJ (1981) Fear, folie and phantom pregnancy. Pseudocyesis in a fifteen year old girl. Br J Psychiatry 139:558-562

12. Kornischka J (2003) Delusion of pregnancy a case report and review of the literature. Psychopathology 36:276-278

13. Shoja MM (2007) Anatomy of the cranial nerves in medieval Persian literature: Esmail Jorjani (AD 1042-1137) and the treasure of the Khwarazm shah. Neurosurgery 61:1325-1330 